\title{
Thermogravimetric and kinetic analysis to discern synergy during the co-pyrolysis of microalgae and swine manure digestate
}

\author{
Arun K. Vuppaladadiyam ${ }^{1}$, Hao Liu ${ }^{2^{*}}$, Ming Zhao ${ }^{1 *} \mathbb{0}$, Abdul F. Soomro ${ }^{1}$, Muhammad Zaki Memon ${ }^{1}$ \\ and Valerie Dupont ${ }^{3}$
}

\begin{abstract}
Background: Co-pyrolysis of wastes with other feedstock can synergistically improve the rate of biomass decomposition and also help to resolve the issues related to limited availability feedstock. In this regards, synergistic interaction between feedstock during co-pyrolysis is an important aspect of research. As the constituents of aquatic and lignocellulosic biomass are different, and the decomposition pattern of aquatic biomass is dissimilar when compared to lignocellulosic biomass, it is important to understand whether these two biomasses interact during co-pyrolysis.

Results: Synergism in the co-pyrolysis of microalgae (MA), swine manure digestate (SWD), and their blends (MA/ SWD) (W/w \%), 2.5/7.5 (MD-1), 5/5 (MD-2), and 7.5/2.5 (MD-3), was evaluated based on decomposition behavior, gas yields, extent of thermal degradation, and kinetics. Extractives and volatiles in biomass enhanced the reaction kinetics and products yields, as indicated by the reduction in apparent activation energy of the blends, accompanied by an increase in $\mathrm{H}_{2}$, total gas yield, and extent in degradation. Thermogravimetric data, via isoconversional methods, were interpreted to achieve the apparent activation energies for the thermal degradation of the MA, SWD, and their blends. The best fit reaction models were identified using compensation effect and generalized master plots methods. Semiquantitative method was used to quantify the evolved gas species. $\mathrm{H}_{2}, \mathrm{CO}$, and $\mathrm{CO}_{2}$ were noted to be the dominant gases, implying that tar cracking and reforming reactions were predominant.
\end{abstract}

Conclusions: Overall, synergy was noticed with respect to the pyrolysis of SWD biomass to gas products in the presence of MA biomass, whereas synergy was witnessed up to $50 \mathrm{w} / \mathrm{w} \%$ MA in view of kinetic parameters as evaluation criteria.

Keywords: Microalgae, Manure, Co-pyrolysis, Isoconversional, Kinetics, Thermogravimetric

\section{Background}

The alternative energy sources, particularly biomass derived biofuels, have been highlighted as substitutes for conventional petroleum fuels. Though, there are numerous advantages associated with biofuels, the first-generation biofuels (produced from edible crops) could result in diverse side effects such as water shortage, increase in

\footnotetext{
*Correspondence: haolu@mail.tsinghua.edu.cn; ming.zhao@tsinghua.edu.cn

'School of Environment, Tsinghua University, Beijing 100084, China ${ }^{2}$ Beijing Guohuan Tsinghua Environmental Engineering Design \& Research Institute Co., Ltd., Beijing, China

Full list of author information is available at the end of the article
}

the price of edible crops, etc. The negative effects associated with the first-generation biofuels, to a major extent, can be eliminated by shifting to the second generation (produced form non-edible biomass) or third generation (produced from aquatic biomass such as macro-/microalgae) as they do not present any threat to food chain or ecosystem [1]. Moreover, microalgae can grow in fresh water, brackish, and wastewater, making them suitable for simultaneous wastewater treatment and biomass generation [2]. In addition, microalgae cultivation can be integrated with large $\mathrm{CO}_{2}$ point sources, such as power or cement plants, and wastewater treatment facilities, 
making it a sustainable pathway for biomass generation coupled with carbon capture [3].

The livestock sector has been reported to be one of the principal contributors to grave environmental issues around the world. In China, it is reported that animal manure is one of the major sources of water pollution, mainly through the transfer of nitrogen $(\mathrm{N})$ and phosphorus (P) [4]. Furthermore, it is estimated that 837 million tons of animal manure are produced in China, 208 million of which contributed by swine manure alone [5]. These considerable amounts of wastes present a serious threat to the environment if they are not managed properly. Furthermore, swine manure is more recognized as a pollutant and is often a derelict bioenergy resource. However, use of manure as a bioenergy feedstock could reduce waste disposal problems and alleviate pressure on environment by providing clean energy [6]. In particular, generation of energy from livestock manure eliminates the most common problems, such as unwanted transfer of pathogens into ecosystem, eutrophication caused by the leaching of nutrients into nearby water bodies, etc., associated with the conventional means of waste management [7].

A wide range of technologies are available for converting biomass to bioenergy, which includes biochemical such as anaerobic digestion, transesterification, fermentation, etc., and thermochemical techniques, such as gasification, liquefaction, pyrolysis, etc. [2]. Till date, anaerobic digestion (AD) has been widely acknowledged as a means to add value and stabilize solid wastes. However, the high $\mathrm{CO}_{2}$ content of biogas generated from $\mathrm{AD}$ process impairs the fuel quality and necessitates several purification steps. In addition, the carbon deposited in the microorganisms lowers the carbon conversion from manure to biofuels. Among the thermochemical conversion techniques, pyrolysis has been the most widely accepted technology to convert biomass, especially agricultural and aquatic biomass, into bioenergy owing to its potential advantages such as less pollution emission, reasonable cost, and simple operation [8]. However, copyrolysis and catalytic pyrolysis help to improve the nature, quantity, and quality of the end products [9]. Furthermore, it is reported that co-pyrolysis of wastes with other feedstock can synergistically improve the rate of biomass decomposition and also help to resolve the issues related to limited availability feedstock [10]. In this regards, synergistic interaction between feedstock during co-pyrolysis is an important aspect of research. As the constituents of aquatic and lignocellulosic biomass are different, and the decomposition pattern of aquatic biomass is dissimilar when compared to lignocellulosic biomass, it is important to understand whether these two biomasses interact during co-pyrolysis. In the former, because of its nutritional value, microalgae decomposition has been mainly related to its lipids, proteins, and carbohydrates content [11], while the latter, intended as biofuel, the decomposition has been mainly studied in terms of its cellulose, hemicellulose, and lignin content [12].

The knowledge of pyrolysis kinetics is essential for many reasons such as predicting the behavior of biomass during pyrolysis which forms the basis for reactor design. A number of successive and/or parallel reactions occur during the thermal breakdown of biomass making it a complicated process. For a thermal decomposition process, the International Confederation for Thermal Analysis and Calorimetry (ICTAC) highly recommends isoconversional methods to identify the 'kinetic triplet' that include apparent activation energy, pre-exponential factor, and reaction mechanism [13, 14]. In the present study, an attempt has been made to evaluate the synergistic influence of microalgae and swine manure digestate during co-pyrolysis as compared to individual pyrolysis. Thermal decomposition behavior of two different category of biomass, namely microalgae and swine manure digestate, and their blends in different ratios have been studied using thermogravimetric analyser coupled with mass spectrometer. Furthermore, the kinetic parameters, which include apparent activation energy $\left(E_{\alpha}\right)$, and preexponential or frequency factor $(A)$ were identified using isoconversional methods (Kissinger-Akahira-Sunose (KAS) [15] and Flynn-Wall-Ozawa (FWO) [16, 17] methods) and compensation effect respectively. The reaction model, $f(\alpha)$, was identified using compensation effect [18] and generalized master plots method [19]. Furthermore, the gases evolved during pyrolysis were analyzed and reported. The most commonly used reaction mechanisms, along with their differential $f(\alpha)$ and integral expressions $g(\alpha)$, are presented in Table 1 .

\section{Methods}

\section{Biomass preparation and characterization}

The microalgae, Spirulina platensis (MA), sample was collected from Phycospectrum Environmental Research Centre (PERC), Chennai, Tamil Nadu, India. The isolated culture was then inoculated and grown in a $1 \mathrm{~L}$ Erlenmeyer flask with working volume of $500 \mathrm{~mL}$ using CFTRI (developed by Central Food and Technology Research Institute, Mysore, India) [20] medium for 30 days. The composition of CFTRI media is presented in Table 2. The cultivation was carried out in an incubator, maintaining a temperature of $30{ }^{\circ} \mathrm{C}$ and a light intensity of $500 \mathrm{~lx}$ throughout the cultivation period. After the cultivation phase, the microalgae cultures were harvested by phase separation in a centrifuge at $6500 \mathrm{rpm}$ for $15 \mathrm{~min}$ to obtain the microalgae biomass. 
Table 1 Common solid-state reaction mechanisms [44, 45]

\begin{tabular}{|c|c|c|}
\hline Reaction mechanisms & Differential form $f(a)$ & Integral form $g(a)$ \\
\hline $\mathrm{A}_{2}$-Nucleation and nuclei growth (Avrami Eq. 1) & $2(1-\alpha)[-\ln (1-\alpha)]^{1 / 2}$ & {$[-\ln (1-\alpha)]^{1 / 2}$} \\
\hline $\mathrm{A}_{3}$-Nucleation and nuclei growth (Avrami Eq. 2) & $3(1-\alpha)[-\ln (1-\alpha)]^{3 / 2}$ & {$[-\ln (1-\alpha)]^{1 / 3}$} \\
\hline $\mathrm{A}_{4}$-Nucleation and nuclei growth (Avrami Eq. 3) & $4(1-\alpha)[-\ln (1-\alpha)]^{3 / 4}$ & {$[-\ln (1-\alpha)]^{1 / 4}$} \\
\hline $\mathrm{R}_{2}$-Phase boundary controlled reaction (contracting area) & $2(1-\alpha)^{1 / 2}$ & {$[1-(1-\alpha)]^{1 / 2}$} \\
\hline $\mathrm{R}_{3}$-Phase boundary controlled reaction (contracting volume) & $3(1-\alpha)^{2 / 3}$ & {$[1-(1-\alpha)]^{1 / 3}$} \\
\hline $\mathrm{D}_{1}$-One-dimensional diffusion & $(1 / 2) \alpha$ & $\alpha^{2}$ \\
\hline $\mathrm{D}_{2}$-Two-dimensional diffusion (Valensi equation) & {$[-\ln (1-\alpha)]^{-1}$} & $(1-\alpha) \ln (1-\alpha)+\alpha$ \\
\hline $\mathrm{D}_{3}$-Three-dimensional diffusion (Jander equation) & $(3 / 2)\left[1-(1-\alpha)^{1 / 3}\right]^{-1}(1-\alpha)^{2 / 3}$ & {$\left[1-(1-\alpha)^{1 / 3}\right]^{2}$} \\
\hline $\mathrm{D}_{4}$-Three-dimensional diffusion (Ginstling-Brounshtein equation) & $(3 / 2)\left[1-(1-\alpha)^{1 / 3}\right]^{-1}$ & $[1-(2 / 3) \alpha)]-(1-\alpha)^{2 / 3}$ \\
\hline $\mathrm{F}_{1}$ - Random nucleation with one nucleus on the individual particle & $1-\alpha$ & $-\ln (1-\alpha)$ \\
\hline $\mathrm{F}_{2}$ - Random nucleation with two nuclei on the individual particle & $(1-\alpha)^{2}$ & $1 /(1-\alpha)$ \\
\hline $\mathrm{F}_{3}$ - Random nucleation with three nuclei on the individual particle & $(1 / 2)(1-\alpha)^{3}$ & $1 /(1-\alpha)^{2}$ \\
\hline$P_{1}-$ Mampel power law $(n=1 / 2)$ & $2 \alpha^{1 / 2}$ & $\alpha^{1 / 2}$ \\
\hline$P_{2}-$ Mampel power law $(n=1 / 3)$ & $3 \alpha^{2 / 3}$ & $\alpha^{1 / 3}$ \\
\hline$P_{3}-$ Mampel power law $(n=1 / 4)$ & $4 \alpha^{3 / 4}$ & $\alpha^{1 / 4}$ \\
\hline
\end{tabular}

Table 2 Composition of CFTRI media [46, 47]

\begin{tabular}{|c|c|}
\hline Chemicals & $\mathrm{g} / \mathrm{LdH}_{2} \mathrm{O}$ \\
\hline $\mathrm{NaHCO}_{3}$ & 4.5 \\
\hline $\mathrm{K}_{2} \mathrm{HPO}_{4}$ & 0.5 \\
\hline $\mathrm{NaNO}_{3}$ & 1.5 \\
\hline $\mathrm{K}_{2} \mathrm{SO}_{4}$ & 1 \\
\hline $\mathrm{NaCl}$ (Crude) & 1 \\
\hline $\mathrm{MgSO}_{4} \cdot 7 \mathrm{H}_{2} \mathrm{O}$ & 0.2 \\
\hline $\mathrm{CaCl}_{2}$ & 0.04 \\
\hline $\mathrm{FeSO}_{4}$ & 0.01 \\
\hline
\end{tabular}

The solid phase biomass was washed with deionized water multiple times and was maintained at $80{ }^{\circ} \mathrm{C}$ in a ventilated oven to procure dried algal biomass.

Partially digested manure was collected from swine manure anaerobic digestion plant Donghua, Beijing. The Automatic Methane Potential Test System II (Bioprocess Control, Sweden) was used to completely digest the sample. The digestion process was run in triplicates, in a $0.6 \mathrm{~L}$ reactors, to ensure the complete digestion. The system consisted of three units: Unit A is a water bath containing 15 glass bottles for anaerobic digestion (AD) and is maintained at mesophilic temperature $\left(35^{\circ} \mathrm{C}\right)$; Unit $\mathrm{B}, \mathrm{CO}_{2}$ adsorption using $3 \mathrm{M}$ sodium hydroxide $(\mathrm{NaOH})$; and Unit $\mathrm{C}$, in which the volume of $\mathrm{CH}_{4}$ released from Unit A was automatically recorded. A mixing rod with slow mechanical rotation was used in each bottle in Unit A. The glass bottles containing manure samples were placed in the water bath in Unit A and only gas generated during the digestion process is allowed to pass to Unit $B$, where bromothymol blue indicator is used to monitor the change in the $\mathrm{pH}$. However, there is no possibility of the manure samples in Unit A to react with $3 \mathrm{M} \mathrm{NaOH}$ in Unit B. The run was stopped after ensuring the methane generation was less than $10 \mathrm{~mL}$ per day. The growth and digestion characteristics of MA and swine manure digestate (SWD), respectively, as they are out of the scope of current study, are not discussed. Elemental analysis was undertaken using a carbon-hydrogen-nitrogen analyzer (model CE 440; EAI, Oakland, NJ, USA), biocompounds (lipid, protein, and carbohydrate) analysis [21], and structural component analysis (lignin, cellulose, and hemicellulose) [22] were carried out as per standard procedures and are presented in Table 3.

\section{TG-DTG-MS analysis}

Thermal analyser (Q600) was used to perform the thermogravimetric (TG) and derivative thermogravimetric (DTG) analyses of individual and blended biomasses. Sample, ca. $3 \mathrm{mg}$ weight, was heated to $800{ }^{\circ} \mathrm{C}$ from ambient temperature. Initially, a constant heating rate of $15{ }^{\circ} \mathrm{C} \mathrm{m^{-1 }}$ was used, and later, the experiments were run at different heating rates of 10 and $20^{\circ} \mathrm{C} \mathrm{min}{ }^{-1}$, from room temperature to $800{ }^{\circ} \mathrm{C}$. For all the experiments, argon (Ar) gas was used as a purge gas and the flow was set at $500 \mathrm{~mL} \mathrm{~min}^{-1}$ to ensure an inert environment. The 
Table 3 Proximate analysis, elemental composition, and chemical composition of biomass samples

\begin{tabular}{llcr}
\hline Parameters & Sample & \multicolumn{1}{l}{ MA } & \multicolumn{1}{l}{ SWD } \\
\hline Proximate analysis (wt\%) & Moisture & $4.76 \pm 0.238$ & $3.9 \pm 0.195$ \\
& VM & $84.25 \pm 2.527$ & $73.76 \pm 2.950$ \\
& FC & $5.85 \pm 0.293$ & $12.62 \pm 0.631$ \\
& Ash & $5.14 \pm 0.103$ & $9.72 \pm 0.243$ \\
Elemental composition & C & $47 \pm 1.88$ & $42.3 \pm 1.904$ \\
(wt\%) & H & $6.8 \pm 0.34$ & $6.1 \pm 0.305$ \\
& O & $27.8 \pm 1.39$ & $41.3 \pm 2.065$ \\
& N & $10.5 \pm 0.53$ & $1.4 \pm 0.07$ \\
& S & $0.82 \pm 0.041$ & $0.71 \pm 0.036$ \\
Chemical composition & Carbohydrate & $19.8 \pm 0.99$ & $21.3 \pm 1.065$ \\
(wt\%) & Protein & $65.2 \pm 1.956$ & $16.3 \pm 0.408$ \\
& Lipid & $8.7 \pm 0.131$ & $7.8 \pm 0.156$ \\
Structural component & Lignin & & $6.49 \pm 0.149$ \\
analysis & Cellulose & & $59.31 \pm 2.966$ \\
& Hemicellulose & & $14.7 \pm 0.441$ \\
\hline
\end{tabular}

Table 4 lon fragments and their representative gas species

\begin{tabular}{lll}
\hline $\boldsymbol{m} / \mathbf{z}$ & lon fragments & Representative species \\
\hline 2 & $\mathrm{H}_{2}^{+}$ & Hydrogen \\
15 & $\mathrm{CH}_{4}^{+}$ & Methane \\
28 & $\mathrm{CO}^{+}$ & Carbon monoxide \\
40 & $\mathrm{Ar}^{+}$ & Argon \\
44 & $\mathrm{CO}_{2}^{+}$ & Carbon dioxide \\
\hline
\end{tabular}

results reported are the average of the data obtained by conducting the experiments in triplicate.

The pyrolysis gas was collected and delivered to the mass spectrometer (MS) by heated capillary, wherein the gas molecules are ionized and differentiated based on their mass-to-charge ratio $(\mathrm{m} / \mathrm{z})$. The ions that were scanned and their respective evolved gases are presented in Table 4.

With respect to the purge flow rate of Ar and weight of biomass, normalization of the raw signals from MS was done based on the following equation:

Normalized signal for key molecule fragments ' $i$ '

$$
=\left(\mathrm{IC}_{i} * 500\right) /\left(\mathrm{IC}_{\mathrm{Ar}} * \mathrm{wt}_{\text {sample }}\right) \text {, }
$$

where, $\mathrm{IC}_{i}$ and $\mathrm{IC}_{\mathrm{Ar}}$ indicate molecular $\mathrm{m} / z$ signals for molecular ion fragments and Ar, ' $i$ ' (arbitrary unit), and $\mathrm{wt}_{\text {sample }}$ indicate the weight of biomass sample $(g)$. The detailed procedure for the analysis of evolved gas species is discussed in our previous study [23].

\section{Kinetic analyses}

Biomass pyrolysis varies for different biomass, mainly because of differences in their chemical structure. However, the overall path of biomass pyrolysis can be defined as follows: Biomass $\rightarrow$ Char + Volatiles + Gases. The rate constant $k(T)$, according to the Arrhenius equation, can be expressed as follows:

$$
k(T)=\mathrm{Ae}^{\left(\frac{-E_{\alpha}}{R T}\right),}
$$

where $A\left(\mathrm{~s}^{-1}\right)$ and $E_{\alpha}\left(\mathrm{J} \mathrm{mol}^{-1}\right)$ are pre-exponential and apparent activation energy of the reaction, respectively, and $R$ and $T\left({ }^{\circ} \mathrm{K}\right)$ are universal gas constant $\left(8.314 \mathrm{~J} \mathrm{~mol}^{-1}\right.$ $\mathrm{K}^{-1}$ ) and absolute temperature, respectively. The kinetics of solid-state thermal degradation can be defined as follows:

$$
\frac{\mathrm{d} \alpha}{\mathrm{d} t}=k(T) f(\alpha)=\mathrm{Ae}^{\left(\frac{-E_{\alpha}}{R T}\right)} f(\alpha),
$$

where $\alpha$ is the degree of conversion at time $t$ and $f(\alpha)$ indicate the reaction mechanism function.

The thermal decomposition is reflected by the conversion degree $\alpha$ which could be defined as follows:

$$
\alpha=\frac{m_{0}-m_{t}}{m_{0}-m_{\infty}}
$$

where $m_{0}, m_{t}$, and $m_{\infty}$ indicate the initial, instantaneous, and final masses during thermal degradation, respectively.

By understanding that temperature increases with respect to time under constant heating rate $(\beta), \beta$ can be expressed as follows:

$$
\beta=\frac{\mathrm{d} T}{\mathrm{~d} t}=\frac{\mathrm{d} T}{\mathrm{~d} \alpha} \times \frac{\mathrm{d} \alpha}{\mathrm{d} t} .
$$

From Eqs. (4) and (2):

$$
\frac{\mathrm{d} \alpha}{\mathrm{d} T}=\frac{A}{\beta} e^{\left(\frac{-E_{\alpha}}{R T}\right)} f(\alpha) .
$$

The integrated form of $f(\alpha)$ can be expressed as follows:

$$
g(\alpha)=\int_{0}^{\alpha} \frac{\mathrm{d} \alpha}{f(\alpha)}=\frac{A}{\beta} \int_{T_{0}}^{T} e^{\left(\frac{-E_{a}}{R T}\right)} \mathrm{d} T .
$$

An exact solution for the above integral cannot be obtained, and thus, Eq. (7) needs to be solved by employing approximations or numerical methods. The isoconversional methods, in view of their good adaptability and validity, are known to provide a viable method to identify the apparent activation energy. Thus, in the present study, two isoconversional methods Kissinger-Akahira-Sunose (KAS) and 
Flynn-Wall-Ozawa (FWO) methods are applied to determine the apparent activation energy.

The FWO method can be expressed as follows:

$$
\ln (\beta)=\ln \left[\frac{A E_{\alpha}}{\operatorname{Rg}(\alpha)}\right]-5.331-1.0516 \frac{E_{\alpha}}{R T} .
$$

The KAS method can be expressed as follows:

$$
\ln \left(\frac{\beta}{T^{2}}\right)=\ln \left[\frac{A R}{E_{\alpha} g(\alpha)}\right]-\frac{E_{\alpha}}{R T} .
$$

At constant conversion rate $(\alpha)$ and multiple heating rates, the plots $\ln \left(\beta / T^{2}\right)$ vs. $1 / T$ (KAS method) and $\ln (\beta)$ vs. $1 / T$ (FWO method) result in straight lines, whose slope can be used to calculate the apparent activation energy. Generalized master plots' methods was used to identify the reaction mechanism function $f(\alpha)$. Theoretical master plots, listed in Table 1, are considered as a reference and were compared against the experimental master plots. The underlying concept related to generalized master plots method is, at infinite temperature, the generalized time $(\theta)$ required to achieve a certain degree of conversion $(\alpha)[24,25]$ can be given by the following equation:

$$
\theta=\int_{0}^{t} e^{\left(\frac{-E \alpha}{R T}\right)} \mathrm{d} t
$$

By differentiating the above equation:

$$
\frac{\mathrm{d} \theta}{\mathrm{d} t}=e^{\left(\frac{-E \alpha}{R T}\right)} .
$$

By combining (1), (2), and (10), we get the following:

$$
\frac{\mathrm{d} \alpha}{\mathrm{d} \theta}=\frac{\mathrm{d} \alpha}{\mathrm{d} t} e^{\left(\frac{-E \alpha}{R T}\right)} .
$$

We can relate a proper kinetic model, by selecting $\alpha=0.5$ as a reference, to reduced generalized rate of reaction as given by the following:

$$
\frac{\frac{\mathrm{d} \alpha}{\mathrm{d} \theta}}{\left(\frac{\mathrm{d} \alpha}{\mathrm{d} \theta}\right) 0.5}=\frac{f(\alpha)}{f(\alpha) 0.5}=\left(\frac{\frac{\mathrm{d} \alpha}{\mathrm{d} \theta}}{\left(\frac{\mathrm{d} \alpha}{\mathrm{d} \theta}\right) 0.5}\right) \frac{e^{\left(\frac{-E \alpha}{R T}\right)}}{e^{\left(\frac{-E \alpha}{R T 0.5}\right)}} .
$$

Therefore, by plotting the generalized reaction rate from the right-hand side of Eq. (13), and the theoretical plots from the left-hand side of Eq. (13) against conversion $(\alpha)$, appropriate reaction mechanism function can be inferred on comparison.

\section{Compensation effect}

While the model free methods are sufficient to determine apparent activation energy, compensation effect allows to accurately determine pre-exponential factor and reaction model. A strong correlation in the form of linear relationship between the Arrhenius parameters, $\ln A_{j}$ and $E_{j}$ estimated using single heating rate method, is known as compensation effect. Taking logarithm on both sides and rearranging terms, Eq. (3) results in Eq. (14):

$$
\ln \left[\frac{1}{f(\alpha)} \frac{\mathrm{d} \alpha}{\mathrm{d} t}\right]=\ln A i(\alpha)-\frac{E \alpha(\alpha)}{R T},
$$

where $i$ indicate the reaction model in Table 1 .

Selecting any reaction model $f_{i}(\alpha)$ mentioned in Table 1 , and by plotting the left-hand side of Eq. (13) against the inverse of temperature, a pair of $\ln A_{i}$ and $E_{\alpha i}$ can be generated from the intercept and slope of straight line. Then the compensation equation is given as follows:

$$
\ln A_{i}=a^{*} E_{\alpha i}+b^{*},
$$

where $a^{\prime \prime}$ and $b^{\prime \prime}$ are generated from linear fitting of these pairs of $\ln A_{i}$ and $E_{\alpha, i}$. By substituting the activation energy obtained from model free isoconversional methods (Eq. 9) and $a^{*}, b^{*}$ values obtained from Eq. (14) in the following equation, the pre-exponential factor at given $\alpha$ can be calculated using the following equation:

$$
\ln A_{\alpha}=a^{*} E_{\alpha}+b^{*},
$$

where $E_{\alpha}$ was obtained from isoconversional methods. By rearranging Eq. (3), the reaction model $f(\alpha)$ can be defined as follows:

$$
f(\alpha)=\left(\frac{\mathrm{d} \alpha}{\mathrm{d} t}\right)_{\alpha}\left[A \alpha \exp \left(-\frac{E \alpha}{R T}\right)\right]^{-1} .
$$

By substituting the experimental values for $(\mathrm{d} \alpha / \mathrm{d} t)$ and $T_{\alpha}$ and using the values of activation energy and pre-exponential factor derived from isoconversional methods and compensation effect, respectively, Eq. (16) yields numerical values for $f(\alpha)$, which can be matched against theoretical $f(\alpha)$ models to identify the most accurate reaction model.

The thermodynamic parameters such as, free Gibbs energy $(\Delta G)$, enthalpy $(\Delta H)$, and change in entropy $(\Delta S)$ were evaluated using Eqs. (18) to (20) [26, 27]:

$$
\begin{aligned}
& \Delta G=E_{\alpha}+R T_{m} \ln \left[\frac{k_{B} T_{m}}{h A}\right] \\
& \Delta H=E_{\alpha}-R T \\
& \Delta S=\frac{\Delta H-\Delta G}{T_{m}},
\end{aligned}
$$

where $\mathrm{T}_{m}, k_{B}$, and $h$ indicate DTG peak temperature, Boltzmann constant $\left(1.381 \times 10^{-23} \mathrm{~J} \mathrm{~K}^{-1}\right)$, and Plank constant $\left(6.626 \times 10^{-34} \mathrm{~J} \mathrm{~s}\right)$, respectively. 


\section{Results and discussion}

\section{Thermal behavior of microalgae, digestate, and their} blends

The TG and DTG curves for the (co-)pyrolysis process for selected biomass samples, which include MA, SWD, and their blends MD-1 (25\% MA+75\% SWD w/w) MD-2 $(50 \% \mathrm{MA}+50 \% \mathrm{SWD} \mathrm{w} / \mathrm{w})$ and MD-3 (75\% MA $+25 \%$ SWD w/w), generated at $15{ }^{\circ} \mathrm{C} \mathrm{min}{ }^{-1}$ heating rate, are presented in Fig. 1.

During pyrolysis, the organic components of biomass are decomposed into different vapor phases and gas compounds leaving a carbon-rich solid residue (pyrolysis char). The mass loss in samples during pyrolysis process is mainly because of evolution of vapor and gas from the biomass. The pyrolysis process of MA, SWD, and their blends (MD-1, 2, and 3) can be divided into three zones. In the first zone, the pyrolysis took place at low temperatures $\left(<200{ }^{\circ} \mathrm{C}\right)$, and this can be attributed to the evaporation of physically absorbed moisture [28]. The main pyrolysis of the plain samples, MA and SWD, took place between 200 and $500{ }^{\circ} \mathrm{C}$, and are in good agreement with the other studies reported in the literature [29, 30]. The second zone could be considered as the main pyrolysis stage as maximum weight loss was noticed in this zone for the individual samples and their blends. For MA sample (Fig. 1a), the second zone occurred in the temperature range $200-600{ }^{\circ} \mathrm{C}$ with a characteristic peak at $315{ }^{\circ} \mathrm{C}$, followed by a shoulder in between 400 and $500{ }^{\circ} \mathrm{C}$. The main peak can be attributed to the decomposition of proteins. The maximum degree of weight loss was noticed at ca. $300-340{ }^{\circ} \mathrm{C}$. As microalgae do not contain cellulose and hemicellulose, weight loss can be attributed to the decomposition of structural components such as lipids, lignin, proteins, and carbohydrates. In this temperature range, these compounds are reported to undergo a set of reaction mechanisms, which include decarboxylation, depolymerization, and cracking of primarily carbohydrates, lipids, and proteins [31]. The small shoulder at the end of the second zone could possibly be the result of lipids and proteins present in microalgae (Table 2).

On the other hand, the DTG profile for the pyrolysis of SWD showed three distinct peaks (Fig. 1b). The main degeneration stage was identified to be in the temperature range $200-500{ }^{\circ} \mathrm{C}$. The main peak was noticed at ca. $330{ }^{\circ} \mathrm{C}$ and can be ascribed to the degradation of hemicellulose and glucoside linkage depolymerisation [30]. Swine manure cannot be considered as common lignocellulosic biomass as it not only contains cellulose, hemicellulose, and lignin, but also contains a large amount of extractives (such as sugars, proteins, lipids, starches, etc.). These extractives cannot be overlooked as they contribute significantly to the total weight of biomass and have a decomposition range matching closely that of hemicellulose [8]. A small shoulder at the right of the major peak can be ascribed to the decomposition either of lipids or of other $N$-containing compounds. In addition, a smaller peak close to $700{ }^{\circ} \mathrm{C}$ was witnessed and this could be because of the dehydration or calcination of mineral components [32]. The DTG profiles of MD-1 (Fig. 1c), MD-2 (Fig. 1d), and MD-3 (Fig. 1e) were similar to the

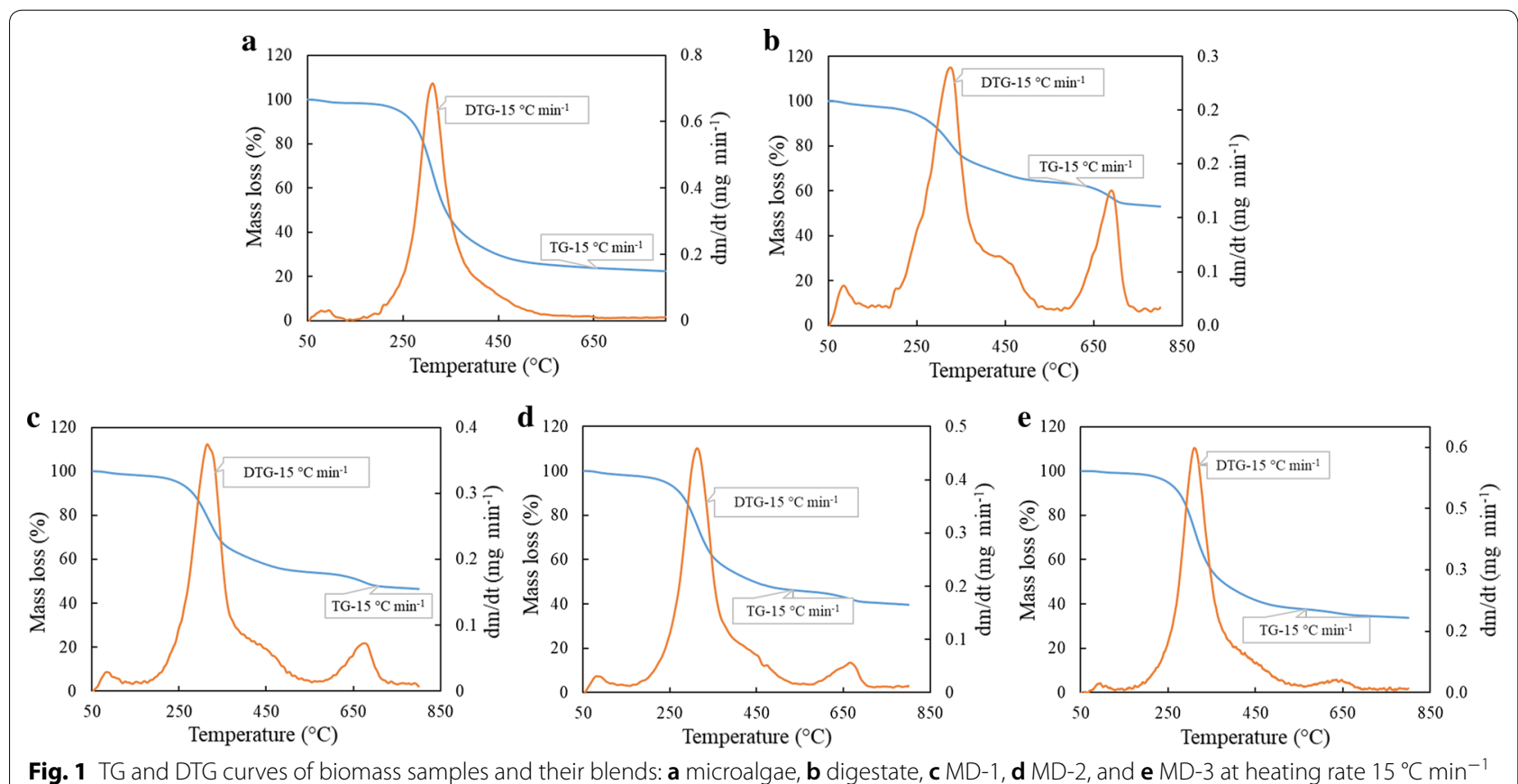

Fig. 1 TG and DTG curves of biomass samples and their blends: a microalgae, $\mathbf{b}$ digestate, $\mathbf{c} \mathrm{MD}-1, \mathbf{d} \mathrm{MD}-2$, and $\mathbf{e} \mathrm{MD}-3$ at heating rate $15^{\circ} \mathrm{C}$ min ${ }^{-1}$ 
biomass that contributed to the major portion of blend. For instance, the DTG profile of MD-1 is similar to that of SWD, while that for MD-3 the DTG profile was close to MAs. However, the peak temperatures of the blends decreased when the proportion of MA was increased. The peak temperatures for MD-1, 2, and 3 were 320, 316, and $314{ }^{\circ} \mathrm{C}$, respectively, with the major weight loss for all the three blends happening in the temperature range of $270-370{ }^{\circ} \mathrm{C}$. When the TGA data of the individual biomass (SWD) are compared against the blends of MA and SWD, no remarkable synergistic effect can be seen during co-pyrolysis, as the amount of solid residue left at the end of co-pyrolysis (at $800{ }^{\circ} \mathrm{C}$ ) is an intermediate value between the residues during the pyrolysis individual biomasses. However, the residues obtained from the pyrolysis of blends were much lower than the SWD pyrolysis residue. This could be because of evolution of hot gaseous species as a result of thermal decomposition of volatile matter or could be because of thermal decomposition of biomass enhanced by catalytic activity of metal contents in the MA and SWD ash [33].

\section{Analysis of evolved gas species}

The gas evolution trends for all the samples are depicted in Fig. 2. There were two distinct phases of gas evolution from pyrolysis. The first gas release coincided with the main pyrolysis weight loss, and the released gases, primarily $\mathrm{CO}$ and $\mathrm{CO}_{2}$, evolved within the temperature range of $250-400{ }^{\circ} \mathrm{C}$. At temperatures $450{ }^{\circ} \mathrm{C}$ and above, $\mathrm{H}_{2}$ released due to tar cracking and reforming reactions was noted and it continued up to $800{ }^{\circ} \mathrm{C}$. There was very little $\mathrm{CH}_{4}$ released during the pyrolysis of all the samples. These appeared to be the general trends of pyrolysis which were shared across all the samples, however, to intensities of gas releases seemed to differ across samples. For MA (Fig. 2a), two $\mathrm{CO}_{2}$ evolution peaks, one at $220{ }^{\circ} \mathrm{C}$ and the other at $324{ }^{\circ} \mathrm{C}$, were noticed. These peaks can be associated with the decomposition of saccharides and main decomposition of proteins and lipids [34]. For SWD (Fig. 2b), two distinct $\mathrm{CO}_{2}$ evolution peaks were noticed at $333{ }^{\circ} \mathrm{C}$ and $688{ }^{\circ} \mathrm{C}$. These can be attributed to the decomposition of volatiles and solid residue respectively, as observed in thermogravimetric analysis of SWD. For the blends (Fig. 2c-MD-1-, Fig. 2d-MD-2, Fig. 2e-MD3 ), with the increase in MA content, the second peak value of $\mathrm{CO}_{2}$ decreased gradually. Similar behavior was observed during the co-pyrolysis of microalgae with textile dying sludge [35]. It can be noticed from Fig. 2 that the $\mathrm{CO}$ evolution trend appeared to be similar for all the samples. The evolution of $\mathrm{CO}$ started from temperatures ca. $200{ }^{\circ} \mathrm{C}$ and continued thorough out the run. The possible reasons could be decomposition of volatiles and Boudouard reactions occurring in temperatures $<500{ }^{\circ} \mathrm{C}$ and $500-800{ }^{\circ} \mathrm{C}$, respectively. For blends, the second evolution peak for $\mathrm{CO}$ followed similar trend as seen for $\mathrm{CO}_{2}$ and the second peak gradually decreased as the proportion of MA grew. The trends from MA and SWD, Fig. 2a, b, showed a similar $\mathrm{H}_{2}$ release, but their $\mathrm{CO}$ and $\mathrm{CO}_{2}$ releases differed. However, there was a mutually synergistic effect on total gas yield between the two biomass types. It can be noticed from Fig. $2 \mathrm{f}$ that the gas yields increased with the rise in the composition of MA in the blends. In addition, the total gas yield was obtained in the order MD-3 $>$ MD-2 $>$ MD-1 $>$ SWD $>$ MA. The plausible reasons for an increase in individual gas compositions as well as total gas yield could be char gasification reactions and reforming reactions. In addition, the alkali metals present in the ash of MA and SWD biomasses could have improved the yield rates and consequently also the final yields.

\section{Evidence of synergy during pyrolysis of biomass blends}

To evaluate quantitatively the possible synergistic effects during the co-pyrolysis of biomass blends, the experimental results (TGA data) were compared with the calculated results, i.e., weighted residual mass values (additive model), if the biomasses had been pyrolysed independently. This is equivalent to a complete lack of synergistic interaction between the two biomass samples during pyrolysis, so that the calculated values are the sum of individual values proportional to their mass ratio. More detailed explanation regarding the procedure can be obtained from the work done by Mallick et al. [33], The weighted residual mass values as functions of time can be obtained from the following equation:

$$
\alpha_{\mathrm{cal}}=\left(1-f_{\mathrm{MA}}\right) \alpha_{\mathrm{SWD}}+f_{\mathrm{MA}} \alpha_{\mathrm{MA}},
$$

where $f_{\mathrm{MA}}$ is the fraction of microalgae in the mixture, and $\alpha_{\mathrm{MA}}$ and $\alpha_{\mathrm{SWD}}$ are the conversions of individual biomasses at a given time. Hence, if individual biomasses are pyrolysed independently, $\alpha_{\text {cal }}$ can be defined as theoretical conversion of a given biomass blend with zero synergy.

Using Eq. (21), the theoretical conversions of biomass blends, calculated by using the TGA data of individual biomasses, are compared with the experimental data and the results are presented in Fig. 3a-c. A significant discrepancy can be noticed between the experimental and calculated profiles of blends MD- 1 and MD-2 and MD-3, especially in the temperature range of $250-650{ }^{\circ} \mathrm{C}$. The experimental thermal degradations of all the blends were more extensive than the calculated additive degradations of individual biomasses of same mass ratio, and this essentially is the evidence of mutual synergy for thermal degradation between the two biomasses and is discussed in greater details in the subsequent sections. 

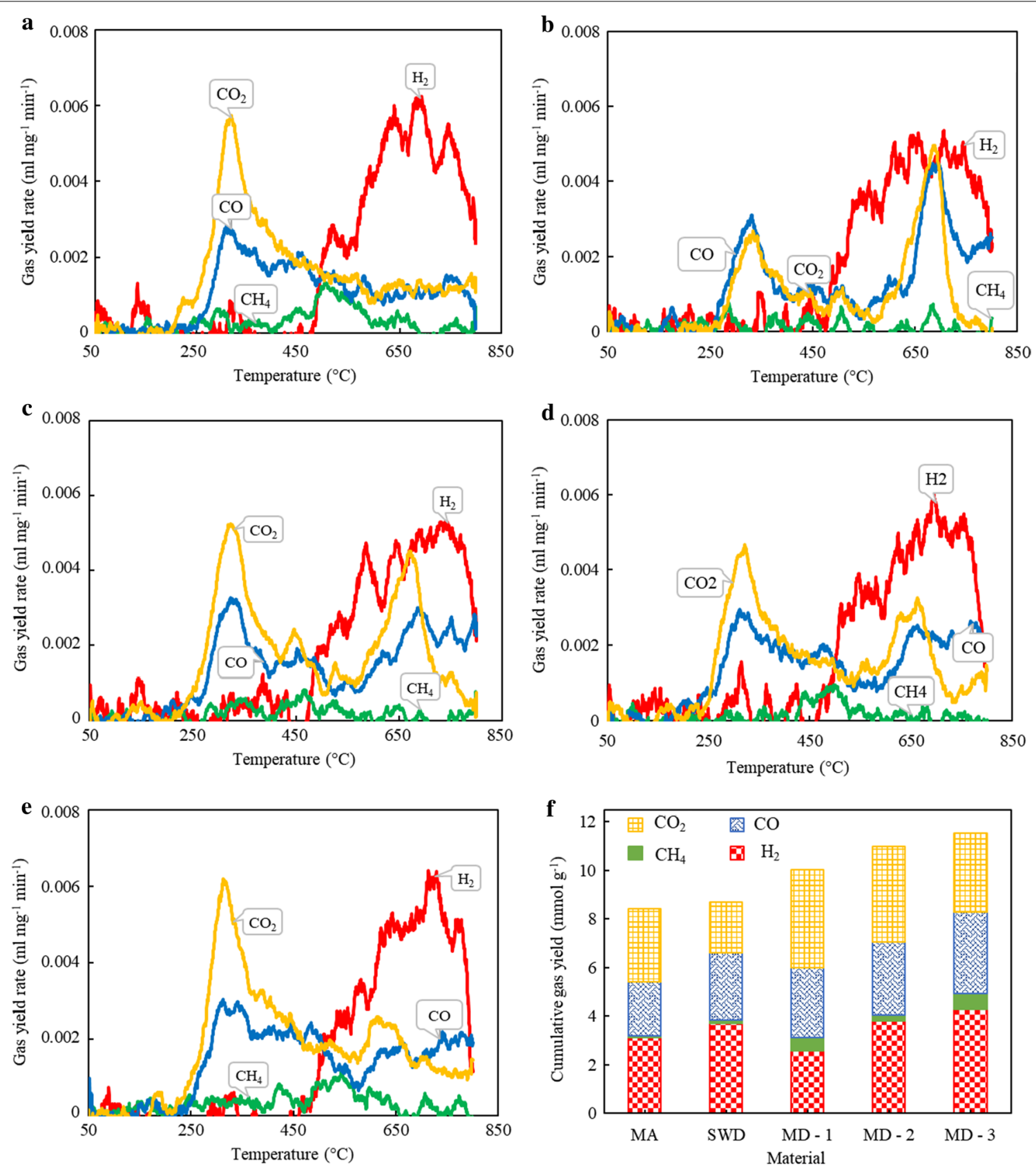

Fig. 2 Gas yield rates for samples: a MA $\mathbf{b}$ SWD, c MD-1, d MD-2, e MD-3, and $\mathbf{f}$ cumulative gas yields for all the samples

\section{Kinetic analysis}

\section{Estimation of apparent activation energy of thermal degradation}

Thermogravimetric data was used to analyze the kinetic parameters of the samples and blends that are considered in the present study. The description of transport phenomena together with chemical kinetics is crucial in the design and optimization of thermochemical conversion systems [36]. Considering the TGA data obtained at heating rates 10,15 , and $20{ }^{\circ} \mathrm{C} \mathrm{min}^{-1}$ and using the isoconversional methods, namely KAS and FWO methods, the apparent activation energies were determined for the materials used in the study. According to Eqs. (7) and (8), the apparent activation energies were calculated within a selected conversion range of $0.1-0.8$ with an interval of 0.05 , and are presented in Table 5. Activation energy is defined as the minimum energy required to initiate a reaction, which imply that a reaction with higher activation energy either need higher reaction temperature or longer duration to gain adequate energy to initiate 

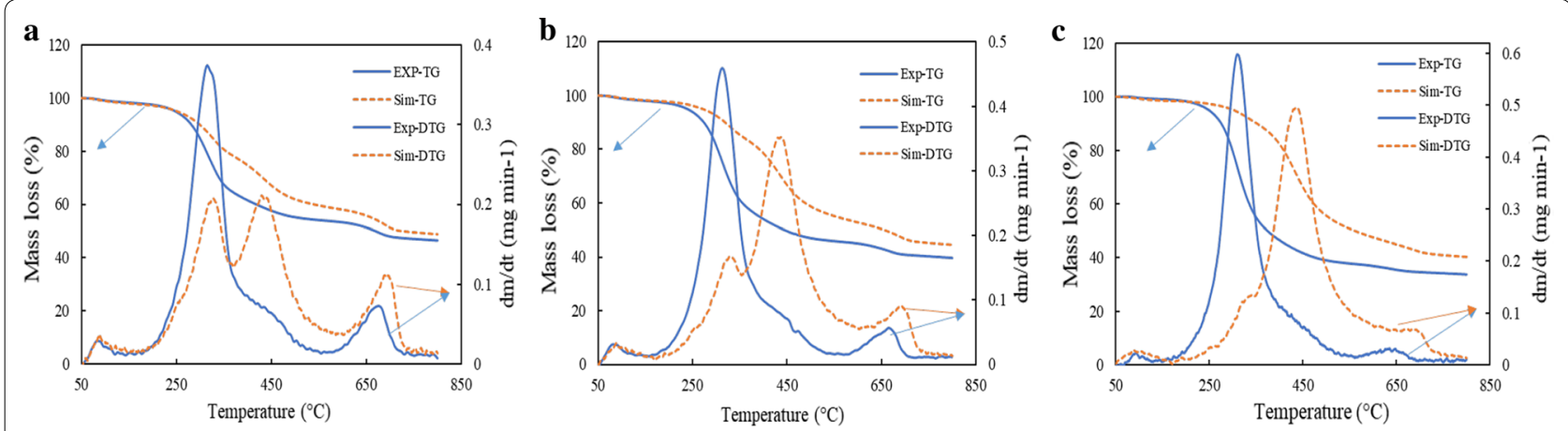

Fig. 3 Comparison of experimental and calculated TGA profiles of biomass for heating rate of $15{ }^{\circ} \mathrm{C} \mathrm{min}^{-1}$ : a MD-1, b MD-2, and $\mathbf{c}$ MD-3

the reaction [37]. When many reactions are present, an apparent activation energy is derived from the data, representative of the ensemble of reactions taking place, as is the case for pyrolysis. The change in the apparent activation energy with respect to conversion is presented in Fig. 4. From Table 5 and Fig. 4, it can be noticed that apparent activation energy $\left(E_{\alpha}\right)$ is highly dependent on conversion which indicates that pyrolysis of biomass is, as expected, a complex process involving many reactions occurring simultaneous at the same stage [38]. The overall pyrolysis process can be characterized as a multi-stage reaction in which every single stage contributes to global mechanism to some extent depending on the decomposition. The average activation energies for samples and their blends using KAS and FWO methods were in the range of 153.17-157.55 for MA, 206.45-209.51 for SWD, 176.07-176.25 for MD-1, 177.13-178.99 for MD-2, and 172.29-172.94 for MD-3. The activation energies obtained in this study are close to the values reported in the literature for similar feedstock. For instance, Shuping et al. [39] and Fernandez-Lopez et al. [40] reported an average range for $E_{\alpha}$ of 145.71-146.42 and 210-213 for microalgae Dunaliella tertiolecta and swine manure, respectively, using KAS and FWO methods.

The $E_{\alpha}$ were noticed to increase from $\alpha=0.15$ which indicate the pyrolysis of main components of biomass (lipid, protein, and carbohydrate in MA and cellulose, hemicellulose, and lignin in SWD). With the increase in the conversion, the pyrolysis of biomasses and their blends can be roughly categorized into different stages (depending on the biomass and their blending ratio). For MA, the pyrolysis with respect to conversion can be divided into two stages: $\alpha=0.1-0.25$ and $\alpha=0.25-0.8$. The temperatures corresponding to stages I and II are $250-300$ and $300-500{ }^{\circ} \mathrm{C}$, respectively. During stage I, the activation energy increased from 160 to $172 \mathrm{~kJ} \mathrm{~mol}^{-1}$. As per the previous literature and DTG curves, discussed above in this study, carbohydrates and proteins of microalgae biomass decomposed in this stage. In the stage II, the activation energy decreased continuously from $164.8 \mathrm{~kJ} \mathrm{~mol}^{-1}$ at $\alpha=0.3$ to $133.1 \mathrm{~kJ} \mathrm{~mol}^{-1}$ at $\alpha=0.8$. For SWD biomass and blends, MD- 1 and MD-2, the pyrolysis process, with respect to conversion, can be divided into three stages. Based on the DTG analysis in this study, it can be inferred that most of the extractives (lipids, proteins, and carbohydrates) and hemicellulose decomposed in stage I, which varied from $\alpha=0.1-0.25$ for SWD and MD- 1 and $\alpha=0.1-0.35$ for MD-2. The difference in the range for MD-1 and MD-2 could be the variation in the proportion of biomasses. In stage I, the $\mathrm{E}_{\alpha}$ values increased from 207.9 to $218.3,139.5$ to 180.3 , and 174 to $190 \mathrm{~kJ} \mathrm{~mol}^{-1}$ for SWD, MD-1, and MD-2, respectively. In stage II, for SWD, the activation energy almost kept a constant value for $\alpha$ varying from 0.25 to 0.55 , while the activation energy decreased continuously from 171 to 164 and $172-153 \mathrm{~kJ} \mathrm{~mol}^{-1}$ for blends MD-1 and 2, respectively. Finally, the activation energies climbed up in stage III as shown in Fig. 4. It should be noted that the behavior of blends is similar to the individual mass-dominant biomass. For MD-3 the trend of activation energy against conversion is similar to MAs. The overall pyrolysis for MD-3 can be divided into two stages, where, in stage I, the activation energy increases continuously to $192.7 \mathrm{~kJ} \mathrm{~mol}^{-1}$ at $\alpha=0.55$ and then decreases to $146.5 \mathrm{~kJ} \mathrm{~mol}^{-1}$ at $\alpha=0.8$. The synergistic effect in co-pyrolysis of biomass is evident in the terms of activation energy. It can be witnessed from Table 4 that average activation energies of blends MD- 1 and 2 have a synergy of SWD with respect to MA in up to $50 \mathrm{w} / \mathrm{w} \%$, as the calculated weighted blend activation energies $(0$ synergy) were higher than those found experimentally. All the blends displayed a higher activation energy than MAs, revealing lack of mutual synergy. The plausible reason could be that the extractives present in MA biomass may not have enhanced the degradation of structural components in SWD biomass, majorly lignin, cellulose, 


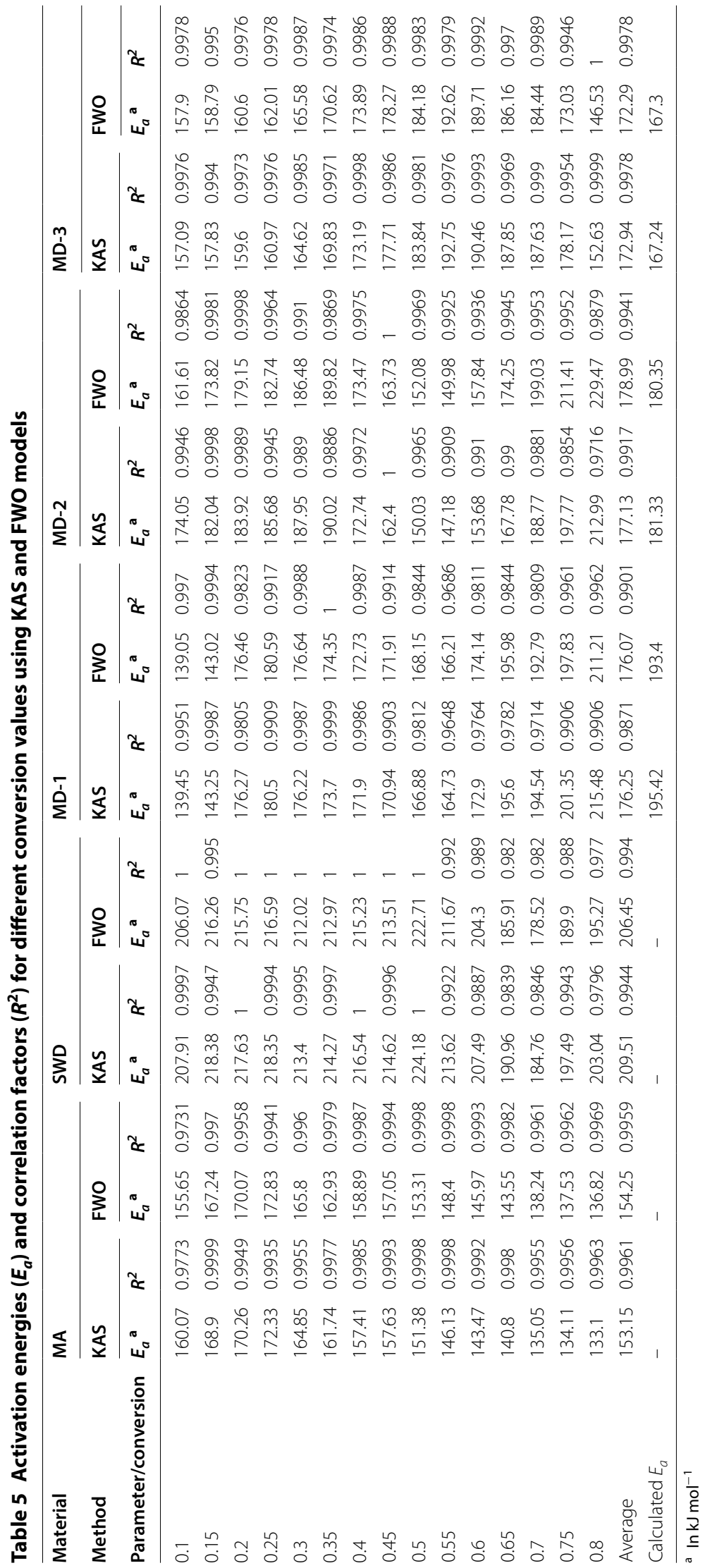



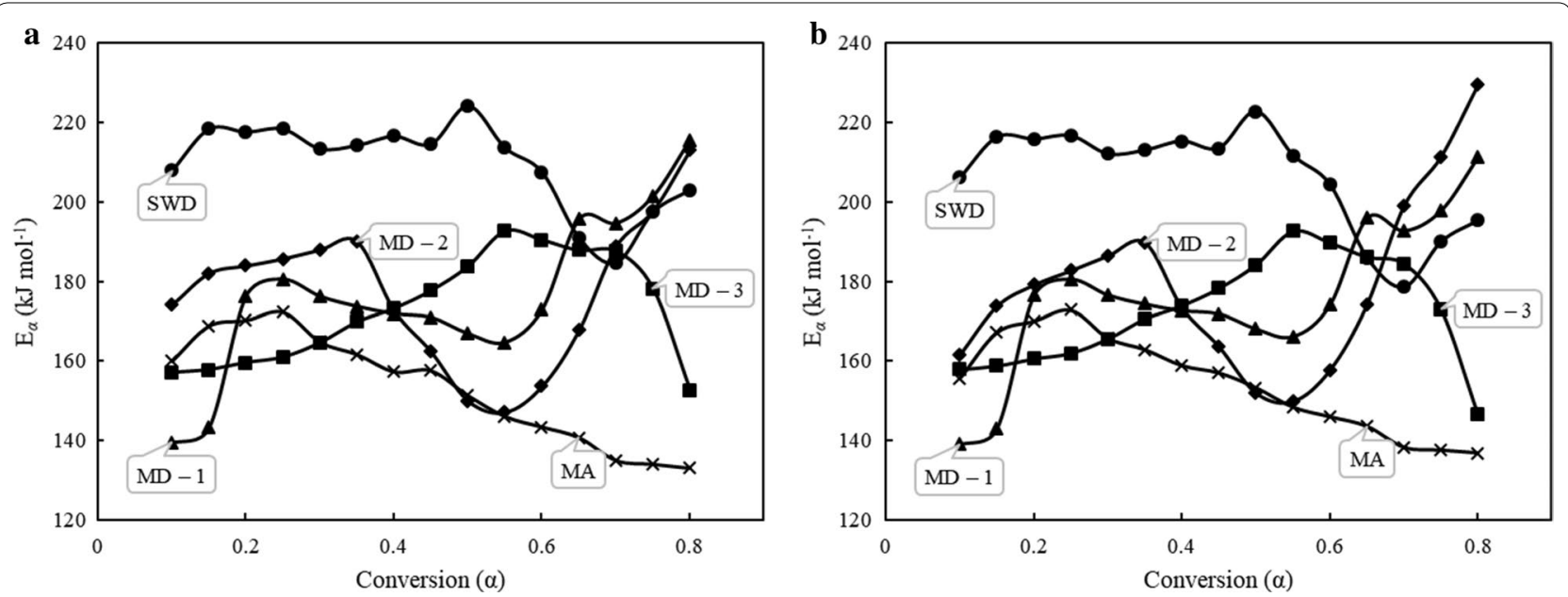

Fig. 4 Variation in activation energy with progressing conversion for $\mathbf{a}$ using KAS and $\mathbf{b}$ using FWO models

and hemicellulose. Furthermore, the synergistic effect of additional heating due to volatiles content is also limited as the SWD biomass contain lower volatiles when compared with other forms of biomass such as lignocellulosic biomass [33]. As a result, the activation energy of blends is marginally higher than that of MA biomass. However, a synergy can be noticed as the average activation energy of blends is significantly lower than pure SWD biomass.

\section{Evaluation of pre-exponential factor and other thermodynamic parameters}

The compensation effect was used to estimate the preexponential factor by using Eqs. (15) and (16), while the other thermodynamic parameters, such as activation enthalpy, activation entropy, and Gibbs free energy, were identified using Eqs. (18)-(20). Using the activation energy obtained using FWO method, pre-exponential factor can be obtained from the compensation line. Considering each $f_{i}(\alpha)$ from Table 1 into Eq. 14, 15 pairs of $\ln A_{i}$ and $E_{\alpha, i}$ are obtained and are plotted in Fig. 5a-e. The variation of $\ln \left(A_{\alpha}\right)$ and $A\left(\mathrm{~s}^{-1}\right)$ with respect to $E_{\alpha}$ is presented in Fig. $5 f-j$ for MA, SWD, MD-1, MD-2, and $\mathrm{MD}-3$, respectively. The values of pre-exponential factor and other thermodynamic parameters for biomasses MA, SWD, and for blends MD-1, 2, and 3 are listed in Table 6 . The pre-exponential factor $(A)$ showed variation in a wide range from $10^{10}$ to $10^{20}$ (depending on material and blending ratio) over the conversion range 0.1-0.8. This reflects the complex nature of biomasses and of the reactions that occur during the process of pyrolysis. The $A$ values $\leq 10^{9} \mathrm{~s}^{-1}$ indicate surface reactions, but, if the reactions are not dependent on the surface area, a low $A$ may also indicate a closed complex (tight junctional complex), while values above $10^{9} \mathrm{~s}^{-1}$ indicate a loose junctional complex [36, 41]. For $A$ ranging in between $10^{10}$ and $10^{12} \mathrm{~s}^{-1}$, when compared to the initial reagent, the activated complex was restricted in rotation [42]. In case of unimolecular materials, the complex is further expected to interact more intensely with its neighbours by expanding its size. From Table 5, within the decomposition range of lignin component $(\alpha=0.5-0.8)$, the values of $A$ of more than $10^{14} \mathrm{~s}^{-1}$ indicate a slower and more difficult degradation effect and imply the need of higher molecular collision. In such case, the reaction demands more energy and this scenario is in agreement with the activation energy characteristics (Table 5).

From Table 6, it is evident that the change in activation enthalpy is in good agreement with the activation energy. It should be noted that, when the difference between $E_{\alpha}$ and $\Delta H$ is minimum, it indicates favorable conditions for the formation of activated complex [43]. From Table 5, when the $E_{\alpha}$ and $\Delta H$ values are compared against each other, a small energy barrier $\left(\sim 5 \mathrm{~kJ} \mathrm{~mol}^{-1}\right)$ indicates the ease of reaction happening under the mentioned conditions. The changes in the Gibbs free energy $(\Delta G)$ indicate the increase in the total energy of the reaction system during the formation of activated complex. The positive values of $\Delta G$ indicate unfavorable conditions and requirement of excess energy as input [33]. The $\Delta G$ values were positive for all the materials and the blends considered in this study. Furthermore, the negative values of $\Delta S$, as well as $\Delta \mathrm{G}$ values higher than $\Delta H$ indicate that a significant amount of heat supplied to the system is unused or free. Entropy $(\Delta S)$ is commonly interpreted as the degree of disorder of the system. A small activation entropy indicates that the material is brought to a new state near its own thermal equilibrium after it has been through some kinds of physical or chemical aging phenomena. On the 

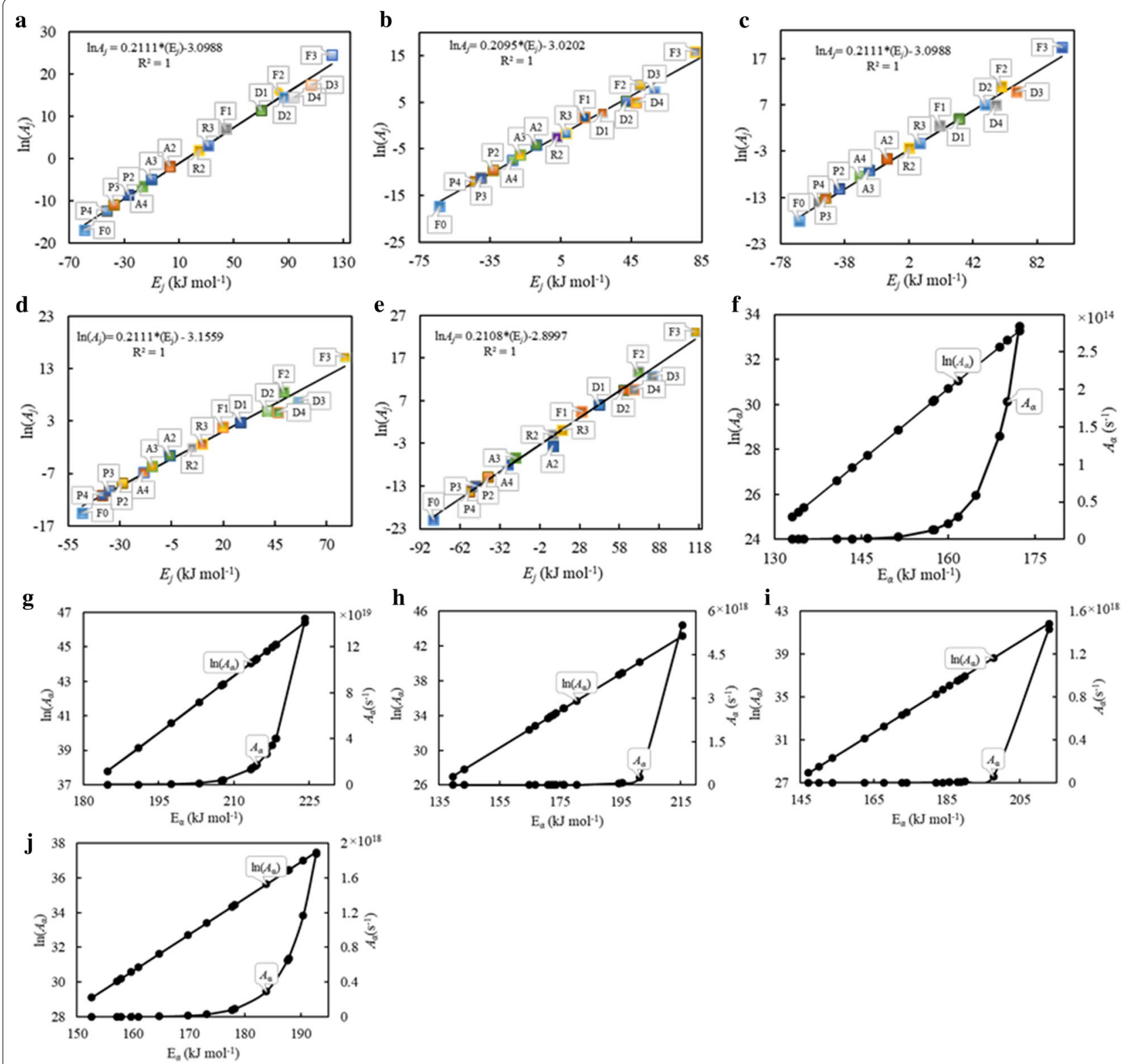

Fig. 5 The compensation line of Arrhenius parameters for a MA, b SWD, c MD-1, d MD-2, and e MD-3; In $A_{a} \vee v$. $E_{a}$ dependencies and $A_{a}$ vs. $E_{\alpha}$ dependencies for $\mathbf{f} M A, \mathbf{g}$ SWD, $\mathbf{h}$ MD-1, i MD-2, and $\mathbf{j} M D-3$

other hand, high values of activation entropy indicate that the material is far from its own thermal equilibrium. In the former case, the material shows little reactivity, which necessitates an increase in reaction time to form an activated complex. In the latter case, the material shows high reactivity and requires shorter reaction time to form an activated complex [42]. As can be seen in Table 6, the $\Delta S$ values for MD-1, 2, and 3 increased from -33.9 to 98.8 , -26.1 to 88.3 , and -16.1 to $51.7 \mathrm{~J} \mathrm{~mol}^{-1}$, indicating an increase in the reactivity of the system.

\section{Evaluation of reaction model}

The generalized master plots are strictly influenced by the kinetic model used to fit the reaction but not by the heating rates. Therefore, in principle, the experimental master plots should take similar shapes for any heating rate. Using Eq. (13), experimental and theoretical master plots for different kinetic models mentioned in Table 1 were compared against each other. In addition, after identifying the pre-exponential factor $(A)$ and apparent activation energy $\left(E_{\alpha}\right)$, the $f(\alpha)$ function 
Table 6 Kinetic and thermodynamic parameters of thermal degradation of MA, SWD, MD-1, MD-2, and MD-3 under the heating rate $(\beta) 15^{\circ} \mathrm{C} \mathrm{min}^{-1}$

\begin{tabular}{|c|c|c|c|c|c|c|}
\hline Material & $\begin{array}{l}\text { Parameter/ } \\
\text { conversion }\end{array}$ & $\begin{array}{l}\text { Activation energy, } E_{a} \\
\left(\mathrm{~kJ} \mathrm{~mol}^{-1}\right)\end{array}$ & $\begin{array}{l}\text { Pre-exponential } \\
\text { factor, } A\left(\mathrm{~s}^{-1}\right)\end{array}$ & $\begin{array}{l}\text { Enthalpy, } \Delta H \\
\left(\mathrm{KJ} \mathrm{mol}^{-1}\right)\end{array}$ & $\begin{array}{l}\text { Gibbs free energy, }{ }^{\circ} \Delta G \\
\left(\mathrm{~kJ} \mathrm{~mol}^{-1}\right)\end{array}$ & $\begin{array}{l}\text { Entropy, }{ }^{\circ} \Delta S \\
\left(\mathrm{~J} \mathrm{~mol}^{-1}\right)\end{array}$ \\
\hline \multirow[t]{15}{*}{ MA } & 0.10 & 155.6 & $7.19 \times 10^{10}$ & 155.6 & 185.1 & -50.37 \\
\hline & 0.15 & 167.2 & $8.91 \times 10^{10}$ & 164.3 & 192.9 & -48.76 \\
\hline & 0.20 & 170.1 & $1.09 \times 10^{11}$ & 165.6 & 193.3 & -47.23 \\
\hline & 0.25 & 172.8 & $3.65 \times 10^{11}$ & 167.6 & 189.4 & -37.24 \\
\hline & 0.30 & 165.8 & $6.41 \times 10^{11}$ & 160.1 & 179.2 & -32.63 \\
\hline & 0.35 & 162.9 & $1.12 \times 10^{12}$ & 156.9 & 173.4 & -28.04 \\
\hline & 0.40 & 158.9 & $3.41 \times 10^{12}$ & 152.6 & 163.6 & -18.88 \\
\hline & 0.45 & 157.1 & $1.22 \times 10^{13}$ & 152.7 & 157.6 & -8.37 \\
\hline & 0.50 & 153.3 & $1.28 \times 10^{13}$ & 146.5 & 151.2 & -8.05 \\
\hline & 0.55 & 148.4 & $2.13 \times 10^{13}$ & 141.1 & 143.4 & -3.85 \\
\hline & 0.60 & 146.0 & $3.04 \times 10^{13}$ & 138.4 & 139.0 & -1.00 \\
\hline & 0.65 & 143.6 & $5.86 \times 10^{13}$ & 135.7 & 133.2 & 4.35 \\
\hline & 0.70 & 138.2 & $1.38 \times 10^{14}$ & 129.9 & 123.2 & 11.32 \\
\hline & 0.75 & 137.5 & $1.84 \times 10^{14}$ & 128.8 & 120.9 & 13.55 \\
\hline & 0.80 & 136.8 & $2.84 \times 10^{14}$ & 127.7 & 117.8 & 16.95 \\
\hline \multirow[t]{15}{*}{ SWD } & 0.10 & 206.1 & $4.08 \times 10^{18}$ & 203.5 & 144.2 & 98.21 \\
\hline & 0.15 & 216.3 & $4.05 \times 10^{19}$ & 213.8 & 143.1 & 117.1 \\
\hline & 0.20 & 215.7 & $3.44 \times 10^{19}$ & 213.0 & 143.2 & 115.6 \\
\hline & 0.25 & 216.6 & $4.03 \times 10^{19}$ & 213.6 & 143.1 & 116.7 \\
\hline & 0.30 & 212.0 & $1.36 \times 10^{19}$ & 208.6 & 143.6 & 107.6 \\
\hline & 0.35 & 213,0 & $1.65 \times 10^{19}$ & 209.4 & 143.5 & 109.1 \\
\hline & 0.40 & 215.2 & $2.71 \times 10^{19}$ & 211.6 & 143.3 & 113.1 \\
\hline & 0.45 & 213.5 & $1.78 \times 10^{19}$ & 209.6 & 143.5 & 109.5 \\
\hline & 0.50 & 222.7 & $1.45 \times 10^{20}$ & 219.2 & 142.5 & 126.9 \\
\hline & 0.55 & 211.7 & $1.43 \times 10^{19}$ & 208.5 & 143.6 & 107.5 \\
\hline & 0.60 & 204.3 & $3.72 \times 10^{18}$ & 202.4 & 144.2 & 96.20 \\
\hline & 0.65 & 185.9 & $9.91 \times 10^{16}$ & 185.7 & 145.9 & 65.93 \\
\hline & 0.70 & 178.5 & $2.55 \times 10^{16}$ & 179.4 & 146.5 & 54.43 \\
\hline & 0.75 & 189.9 & $4.15 \times 10^{17}$ & 192.0 & 145.2 & 77.36 \\
\hline & 0.80 & 195.3 & $1.4 \times 10^{18}$ & 197.3 & 144.7 & 87.15 \\
\hline \multirow[t]{15}{*}{ MD-1 } & 0.10 & 139.1 & $5.2 \times 10^{11}$ & 134.6 & 154.6 & -33.88 \\
\hline & 0.15 & 143.0 & $1.17 \times 10^{12}$ & 138.4 & 154.6 & -27.34 \\
\hline & 0.20 & 176.5 & $1.13 \times 10^{14}$ & 171.8 & 165.6 & 10.53 \\
\hline & 0.25 & 180.6 & $1.78 \times 10^{14}$ & 175.9 & 167.5 & 14.22 \\
\hline & 0.30 & 176.6 & $4.22 \times 10^{14}$ & 171.9 & 159.2 & 21.31 \\
\hline & 0.35 & 174.3 & $5.19 \times 10^{14}$ & 169.5 & 156.0 & 22.93 \\
\hline & 0.40 & 172.7 & $6.41 \times 10^{14}$ & 167.8 & 153.3 & 24.61 \\
\hline & 0.45 & 171.9 & $7.61 \times 10^{14}$ & 167.0 & 151.6 & 25.96 \\
\hline & 0.50 & 168.1 & $1.3 \times 10^{15}$ & 163.2 & 145.2 & 30.34 \\
\hline & 0.55 & 166.2 & $1.32 \times 10^{15}$ & 161.2 & 143.2 & 30.34 \\
\hline & 0.60 & 174.1 & $3.23 \times 10^{15}$ & 169.1 & 146.7 & 37.73 \\
\hline & 0.65 & 196.0 & $6.41 \times 10^{16}$ & 190.8 & 153.8 & 62.47 \\
\hline & 0.70 & 192.8 & $8.03 \times 10^{16}$ & 187.7 & 149.6 & 64.18 \\
\hline & 0.75 & 197.8 & $2.73 \times 10^{17}$ & 192.5 & 148.6 & 74.13 \\
\hline & 0.80 & 211.2 & $5.53 \times 10^{18}$ & 205.7 & 147.1 & 98.83 \\
\hline
\end{tabular}


Table 6 (continued)

\begin{tabular}{|c|c|c|c|c|c|c|}
\hline Material & $\begin{array}{l}\text { Parameter/ } \\
\text { conversion }\end{array}$ & $\begin{array}{l}\text { Activation energy, } E_{\alpha} \\
\left(\mathrm{kJ} \mathrm{mol}^{-1}\right)\end{array}$ & $\begin{array}{l}\text { Pre-exponential } \\
\text { factor, } A\left(s^{-1}\right)\end{array}$ & $\begin{array}{l}\text { Enthalpy, } \Delta H \\
\left(\mathrm{~kJ} \mathrm{~mol}^{-1}\right)\end{array}$ & $\begin{array}{l}\text { Gibbs free energy, }{ }^{\circ} \Delta G \\
\left(\mathrm{~kJ} \mathrm{~mol}^{-1}\right)\end{array}$ & $\begin{array}{l}\text { Entropy, }{ }^{\circ} \Delta S \\
\left(\mathrm{~J} \mathrm{~mol}^{-1}\right)\end{array}$ \\
\hline \multirow[t]{15}{*}{ MD-2 } & 0.10 & 161.6 & $1.33 \times 10^{12}$ & 157.1 & 172.5 & -26.08 \\
\hline & 0.15 & 173.8 & $2.42 \times 10^{12}$ & 169.2 & 181.8 & -21.41 \\
\hline & 0.20 & 179.1 & $5.23 \times 10^{12}$ & 174.5 & 183.3 & -15.10 \\
\hline & 0.25 & 182.7 & $3.3 \times 10^{13}$ & 178.0 & 177.9 & 0.21 \\
\hline & 0.30 & 186.5 & $1.03 \times 10^{14}$ & 181.7 & 176.1 & 9.65 \\
\hline & 0.35 & 189.8 & $2.93 \times 10^{14}$ & 185.0 & 174.3 & 18.33 \\
\hline & 0.40 & 173.5 & $3.85 \times 10^{14}$ & 168.6 & 156.6 & 20.56 \\
\hline & 0.45 & 163.7 & $2.08 \times 10^{15}$ & 158.8 & 138.6 & 34.61 \\
\hline & 0.50 & 152.1 & $3.1 \times 10^{15}$ & 147.1 & 124.9 & 37.86 \\
\hline & 0.55 & 150.0 & $4.49 \times 10^{15}$ & 145.0 & 121.0 & 40.88 \\
\hline & 0.60 & 157.8 & $7.25 \times 10^{15}$ & 152.8 & 126.5 & 44.80 \\
\hline & 0.65 & 174.2 & $8.62 \times 10^{15}$ & 169.1 & 142.1 & 46.15 \\
\hline & 0.70 & 199.0 & $1.12 \times 10^{16}$ & 193.8 & 165.6 & 48.21 \\
\hline & 0.75 & 211.4 & $5.76 \times 10^{16}$ & 206.1 & 169.9 & 61.69 \\
\hline & 0.80 & 229.5 & $1.43 \times 10^{18}$ & 224.0 & 172.2 & 88.32 \\
\hline \multirow[t]{15}{*}{ MD-3 } & 0.10 & 158.0 & $4.45 \times 10^{12}$ & 153.4 & 162.8 & -16.06 \\
\hline & 0.15 & 159.0 & $1.13 \times 10^{13}$ & 154.2 & 159.2 & -8.51 \\
\hline & 0.20 & 161.0 & $1.31 \times 10^{13}$ & 156,0 & 160.3 & -7.35 \\
\hline & 0.25 & 162.0 & $1.90 \times 10^{13}$ & 157.3 & 159.9 & -4.40 \\
\hline & 0.30 & 165.6 & $2.52 \times 10^{13}$ & 160.8 & 162.1 & -2.10 \\
\hline & 0.35 & 170.6 & $5.39 \times 10^{13}$ & 165.8 & 163.4 & 4.13 \\
\hline & 0.40 & 173.9 & $1.59 \times 10^{14}$ & 169.0 & 161.4 & 13.08 \\
\hline & 0.45 & 178.3 & $3.2 \times 10^{14}$ & 173.4 & 162.3 & 18.81 \\
\hline & 0.50 & 184.2 & $8.21 \times 10^{14}$ & 179.3 & 163.6 & 26.56 \\
\hline & 0.55 & 192.6 & $9.03 \times 10^{14}$ & 187.64 & 171.6 & 27.27 \\
\hline & 0.60 & 189.7 & $2.94 \times 10^{15}$ & 184.7 & 163.0 & 36.99 \\
\hline & 0.65 & 186.2 & $6.46 \times 10^{15}$ & 181.1 & 155.6 & 43.44 \\
\hline & 0.70 & 184.4 & $6.76 \times 10^{15}$ & 179.3 & 153.6 & 43.68 \\
\hline & 0.75 & 173.0 & $1.16 \times 10^{16}$ & 167.7 & 139.6 & 48.01 \\
\hline & 0.80 & 146.5 & $1.87 \times 10^{16}$ & 141.1 & 110.7 & 51.73 \\
\hline
\end{tabular}

is numerically evaluated by using (17). The $f(\alpha)$ functions deduced from compensation effect and generalized master plots method for the materials studied are presented in Fig. 6, MA (Fig. 6a, b), SWD (Fig. 6c, d), MD-1 (Fig. 6e, f), MD-2 (Fig. 6g, h), and MD-3 (Fig. 6i, j). Though there are a number of reaction models available (Table 1), they can be categorized into three major groups describing the rate of change of conversion with temperature; accelerating, decelerating, and sigmoidal. The $f(\alpha)$ deduced from compensation effect can be used to categorize the reaction model into any of these three categories, while generalized master plots methods can be used to match experimental $f(\alpha)$ curves to theoretically available models. For sample MA, the experimental reaction model deduced using compensation effect indicates $f(\alpha)$ as a monotone function decreasing continuously with conversion. Based on the progression of $f(\alpha)$ with respect to conversion, $f(\alpha)$ can be classified into order-based models. This finding is in accordance with the curve obtained using the master plots method. The experimental curve closely matches with random nucleation with three nuclei on the individual particle (F3) reaction model (Fig. 6a, b). Similar trend was witnessed for SWD biomass sample, where the $f(\alpha)$ generated by using compensation effect was found to decrease continuously with the extent of conversion. This type of behavior can be related to reaction-order models or diffusion models.

It can be understood from Fig. $6 \mathrm{~d}$, that the $f(\alpha)$ function followed three-dimensional diffusion (Jander equation) (D3) in the entire conversion range. For blends MD-1 and MD-2, the experimental curves closely matched to D3 mechanism at lower conversions $(\alpha<0.5)$ and then shifted to F3 mechanism at higher conversions. The reaction model of MD-3 was similar to that of MA biomass for conversions $>0.2$. However, at lower conversions 

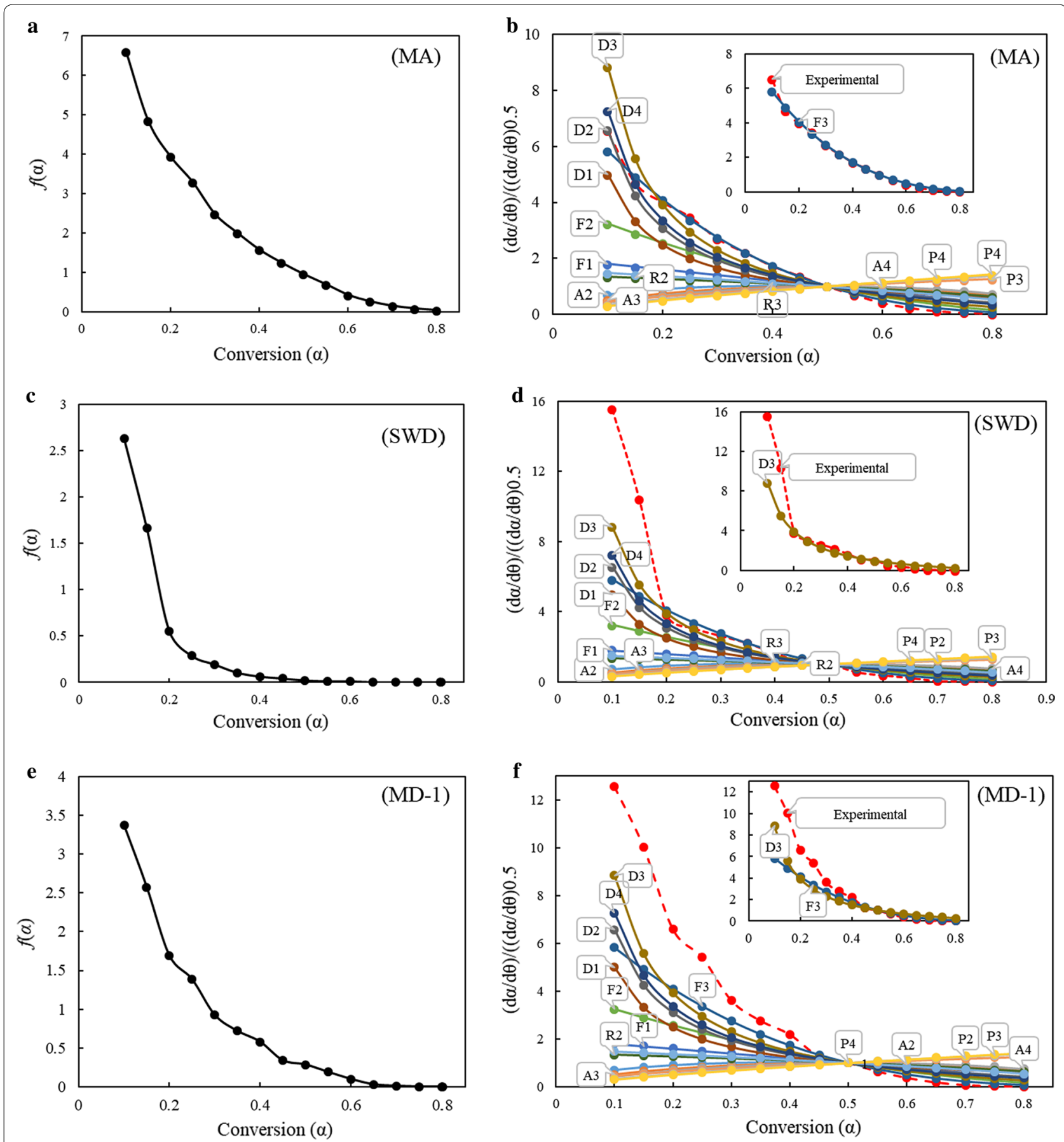

Fig. $\mathbf{6}$ Reaction mechanisms for samples obtained (a), (c), (e), (g) and (i) using compensation effect (on the left) and (b), (d), (f), (h) and (j) using generalized master plots method (on the right side)

$(\alpha<0.2)$, the blend MD-3 was in between D3 and threedimensional diffusion (Ginstling-Brounshtein equation) (D4) mechanisms. Intuitive reasons why the 3D nucleation and nuclei growth model provided a better fit with MA samples, while the 3D diffusion model fitted best the SWD samples, can be supported by their different compositions and structures. Lack of lignin/cellulose/hemicellulose in MA samples resulted in a faster decomposition concurrent with low temperature evolution of $\mathrm{CO}$ and $\mathrm{CO}_{2}$. In contrast, SWD with cellulose (potentially crystalline), hemicellulose, and lignin which are harder to degrade, would need to overcome solid 

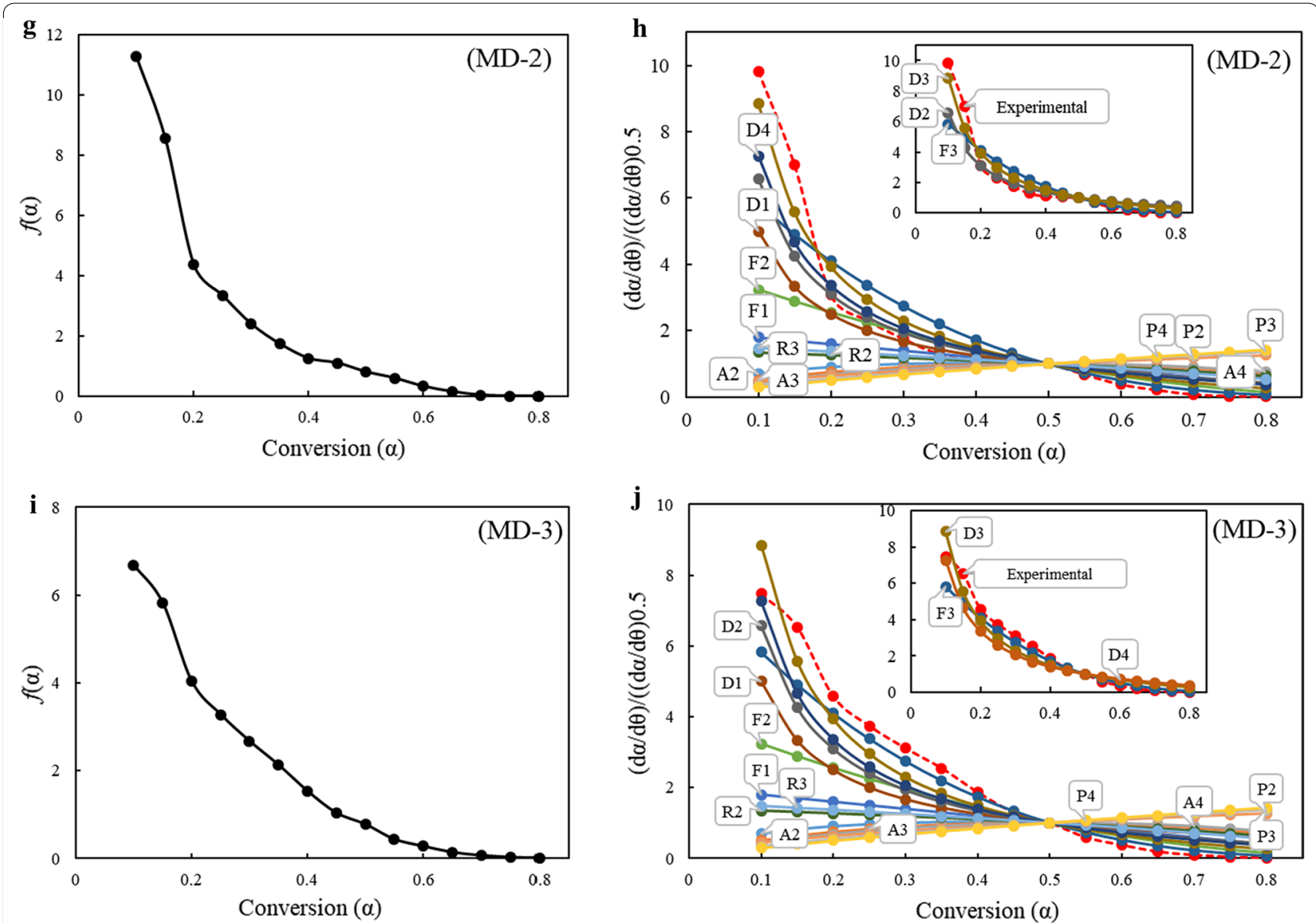

Fig. 6 (continued)

diffusion barriers, resulting in a wider spread evolution of the $\mathrm{CO}$ and $\mathrm{CO}_{2}$ gas products towards the higher temperatures. Decarboxylation and decarbonylation would occur more readily via nuclei and nuclei growth mechanism on the easily accessed solid reagents in the absence of strong fibre components, such as cellulose, hemicellulose, and lignin. The synergy would be reflected in a larger influence of 3D nucleation and nuclei growth than expected, and lowered diffusion barriers consistent with ash catalyzed reactions.

\section{Conclusions}

The present study attempts to investigate the synergistic impact of microalgae biomass during its co-pyrolysis with swine manure digestate. TG and DTG profiles of plain and blended samples showed three zones of devolatilization. The volatiles and extractives in the biomass samples enhanced the kinetics of thermal decomposition of biomass blends. The mineral content of the ash in the blends enhanced their kinetics, which is evident based on gas yields and low activation energy with blends when compared to SWD biomass. If heat flow and disorder change are comprehensively evaluated, the higher activation $\Delta G$ values indicated favorability for the reactions to happen. The synergy between biomasses was evident in the gas evolution trends, as the total gas yield was noticed to increase with increase in the proportion of MA in the blends. In addition, the second evolution peaks of $\mathrm{CO}_{2}$ and $\mathrm{CO}$ were found to decrease with a rise in the proportion of MA.

Authors' contributions

The manuscript was written through contributions of all authors. All authors read and approved the final manuscript.

\section{Funding sources}

The work was supported by National Natural Science Foundation of China (Grant Number: 51506112) and Tsinghua University Initiative Scientific Research Program (Grant Number: 20161080094).

\section{Availability of data and materials Not applicable.}

Ethics approval and consent to participate Not applicable.

Consent for publication

Authors agreed to publish this article. 


\section{Competing interests}

The authors declare that they have no competing interests.

\section{Author details}

${ }^{1}$ School of Environment, Tsinghua University, Beijing 100084, China. ${ }^{2}$ Beijing Guohuan Tsinghua Environmental Engineering Design \& Research Institute Co., Ltd., Beijing, China. ${ }^{3}$ School of Chemical and Process Engineering, The University of Leeds, Leeds LS2 9JT, UK.

Received: 7 April 2019 Accepted: 7 June 2019

Published online: 29 June 2019

\section{References}

1. Vuppaladadiyam AK, Prinsen P, Raheem A, Luque R, Zhao M. Microalgae cultivation and metabolites production: a comprehensive review. Biofuels Bioprod Biorefin. 2018;12(2):304-24.

2. Raheem A, Prinsen P, Vuppaladadiyam AK, Zhao M, Luque R. A review on sustainable microalgae based biofuel and bioenergy production: recent developments. J Clean Prod. 2018;181:42-59.

3. Vuppaladadiyam AK, Yao JG, Florin N, George A, Wang X, Labeeuw L, et al. Impact of flue gas compounds on microalgae and mechanisms for carbon assimilation and utilization. Chemsuschem. 2018;11(2):334-55.

4. Bai Z, Ma L, Qin W, Chen Q, Oenema O, Zhang F. Changes in pig production in China and their effects on nitrogen and phosphorus use and losses. Environ Sci Technol. 2014;48(21):12742-9.

5. Zhou J, Zhang R, Liu F, Yong X, Wu X, Zheng T, et al. Biogas production and microbial community shift through neutral pH control during the anaerobic digestion of pig manure. Bioresour Technol. 2016;217:44-9.

6. Shen X, Huang G, Yang Z, Han L. Compositional characteristics and energy potential of Chinese animal manure by type and as a whole. Appl Energy. 2015;160:108-19.

7. Jeong K-H, Choi D-H, Lee D-J, Kim JK, Kim H, Ok YS, et al. $\mathrm{CO}_{2}$-looping in pyrolysis of horse manure using $\mathrm{CaCO}_{3}$. J Clean Prod. 2018;174:616-24.

8. Yuan X, He T, Cao H, Yuan Q. Cattle manure pyrolysis process: kinetic and thermodynamic analysis with isoconversional methods. Renewable Energy. 2017;107:489-96.

9. Hassan H, Lim JK, Hameed BH. Recent progress on biomass co-pyrolysis conversion into high-quality bio-oil. Bioresour Technol. 2016;221:645-55.

10. Oyedun AO, Tee CZ, Hanson S, Hui CW. Thermogravimetric analysis of the pyrolysis characteristics and kinetics of plastics and biomass blends. Fuel Process Technol. 2014;128:471-81.

11. Wang $X$, Tang $X$, Yang X. Pyrolysis mechanism of microalgae Nannochloropsis sp. based on model compounds and their interaction. Energy Conv Manag. 2017;140:203-10.

12. Wang S, Dai G, Yang H, Luo Z. Lignocellulosic biomass pyrolysis mechanism: a state-of-the-art review. Prog Energy Combust Sci. 2017;62:33-86.

13. Zhao B, Xu X, Li H, Chen X, Zeng F. Kinetics evaluation and thermal decomposition characteristics of co-pyrolysis of municipal sewage sludge and hazelnut shell. Bioresour Technol. 2018;247(Supplement C):21-9.

14. Vyazovkin S. Some basics en route to isoconversional methodology. Isoconversional kinetics of thermally stimulated processes. Berlin: Springer; 2015. p. 1-25.

15. Akahira T, Sunose T. Method of determining activation deterioration constant of electrical insulating materials. Res Rep Chiba Inst Technol (Sci Technol). 1971;16:22-31.

16. Ozawa T. A new method of analyzing thermogravimetric data. Bull Chem Soc Jpn. 1965;38(11):1881-6.

17. Flynn JH, Wall LA. General treatment of the thermogravimetry of polymers. J Res Nat Bur Stand. 1966;70(6):487-523.

18. Vyazovkin S, Sbirrazzuoli N. Isoconversional kinetic analysis of thermally stimulated processes in polymers. Macromol Rapid Commun. 2006;27(18):1515-32.

19. Sánchez-Jiménez PE, Pérez-Maqueda LA, Perejón A, Criado JM. Generalized master plots as a straightforward approach for determining the kinetic model: the case of cellulose pyrolysis. Thermochim Acta. 2013;552:54-9.
20. Venkataraman LV, Becker EW. Biotechnology and utilization of algae: the Indian experience. New Delhi: Department of Science \& Technology and Central Food Technological Research; 1985.

21. Apha. Standard methods for the examination of water and wastewater. Washington: American Public Health Association; 2012. p. 1496.

22. Ven Soest $P$. Use of detergents in the analysis of fibrous feeds Determination of plant cell wall constituents. J Assoc Off Anal Chem. 1967;50:50-5.

23. Vuppaladadiyam AK, Memon MZH, Ji G, Raheem A, Jia TZ, Dupont V, et al. Thermal characteristics and kinetic analysis of woody biomass pyrolysis in presence of bifunctional alkali metal ceramics. ACS Sustain Chem Eng. 2018;7:1.

24. Vyazovkin S. Kinetic concepts of thermally stimulated reactions in solids: a view from a historical perspective. Int Rev Phys Chem. 2000;19(1):45-60.

25. Zubair M, Shehzad F, Al-Harthi MA. Impact of modified graphene and microwave irradiation on thermal stability and degradation mechanism of poly (styrene-co-methyl meth acrylate). Thermochim Acta. 2016;633:48-55.

26. Huang L, Xie C, Liu J, Zhang X, Chang K, Kuo J, et al. Influence of catalysts on co-combustion of sewage sludge and water hyacinth blends as determined by TG-MS analysis. Bioresour Technol. 2018;247:217-25.

27. Kim YS, Kim YS, Kim SH. Investigation of thermodynamic parameters in the thermal decomposition of plastic waste-waste lube oil compounds. Environ Sci Technol. 2010:44(13):5313-7.

28. Hu Z, Chen Z, Li G, Chen X, Hu M, Laghari M, et al. Characteristics and kinetic studies of Hydrilla verticillata pyrolysis via thermogravimetric analysis. Bioresour Technol. 2015;194:364-72.

29. Rizzo AM, Prussi M, Bettucci L, Libelli IM, Chiaramonti D. Characterization of microalga Chlorella as a fuel and its thermogravimetric behavior. Appl Energy. 2013;102:24-31.

30. Fernandez-Lopez M, Puig-Gamero M, Lopez-Gonzalez D, Avalos-Ramirez A, Valverde J, Sanchez-Silva L. Life cycle assessment of swine and dairy manure: pyrolysis and combustion processes. Bioresour Technol. 2015:182:184-92.

31. Söyler N, Goldfarb JL, Ceylan S, Saçan MT. Renewable fuels from pyrolysis of Dunaliella tertiolecta: an alternative approach to biochemical conversions of microalgae. Energy. 2017;120:907-14.

32. Wnetrzak R, Kwapinski W, Peters K, Sommer SG, Jensen LS, Leahy JJ. The influence of the pig manure separation system on the energy production potentials. Bioresour Technol. 2013;136:502-8.

33. Mallick D, Poddar MK, Mahanta P, Moholkar VS. Discernment of synergism in pyrolysis of biomass blends using thermogravimetric analysis. Bioresour Technol. 2018:261:294-305.

34. López-González D, Fernandez-Lopez M, Valverde J, Sanchez-Silva L. Pyrolysis of three different types of microalgae: kinetic and evolved gas analysis. Energy. 2014;73:33-43.

35. Peng $X$, Ma X, Lin Y, Guo Z, Hu S, Ning X, et al. Co-pyrolysis between microalgae and textile dyeing sludge by TG-FTIR: kinetics and products. Energy Convers Manage. 2015;100:391-402.

36. Maia AAD, de Morais LC. Kinetic parameters of red pepper waste as biomass to solid biofuel. Bioresour Technol. 2016;204:157-63.

37. Chen C, Ma X, He Y. Co-pyrolysis characteristics of microalgae Chlorella vulgaris and coal through TGA. Bioresour Technol. 2012;117:264-73.

38. Garcia-Maraver A Perez-Jimenez JA, Serrano-Bernardo F, Zamorano M. Determination and comparison of combustion kinetics parameters of agricultural biomass from olive trees. Renewable Energy. 2015:83:897-904.

39. Shuping Z, Yulong W, Mingde $Y$, Chun L, Junmao T. Pyrolysis characteristics and kinetics of the marine microalgae Dunaliella tertiolecta using thermogravimetric analyzer. Bioresour Technol. 2010;101(1):359-65.

40. Fernandez-Lopez M, Pedrosa-Castro GJ, Valverde JL, Sanchez-Silva L. Kinetic analysis of manure pyrolysis and combustion processes. Waste Manage. 2016;58:230-40.

41. Turmanova SC, Genieva S, Dimitrova A, Vlaev L. Non-isothermal degradation kinetics of filled with rise husk ash polypropene composites. Express Polymer Letters. 2008;2(2):133-46.

42. $\mathrm{Xu} Y, \mathrm{Chen} \mathrm{B}$. Investigation of thermodynamic parameters in the pyrolysis conversion of biomass and manure to biochars using thermogravimetric analysis. Bioresour Technol. 2013;146:485-93.

43. Mehmood MA, Ye G, Luo H, Liu C, Malik S, Afzal I, et al. Pyrolysis and kinetic analyses of Camel grass (Cymbopogon schoenanthus) for bioenergy. Bioresour Technol. 2017;228:18-24. 
44. Poletto M, Zattera AJ, Santana RMC. Thermal decomposition of wood: kinetics and degradation mechanisms. Bioresour Technol. 2012;126:7-12.

45. Ali I, Naqvi SR, Bahadar A. Kinetic analysis of Botryococcus braunii pyrolysis using model-free and model fitting methods. Fuel. 2018;214:369-80.

46. Nyabuto DK, Kewei C, Mariga AM, Kibue GW, Meilin H, Changhai W. Growth performance and biochemical analysis of the genus Spirulina under different physical and chemical environmental factors. Afr J Agric Res. 2015;10(36):3614-24
47. Pandey J, Tiwari A, Mishra R. Evaluation of biomass production of Spirulina maxima on different reported media. J Algal Biomass UtIn. 2010;1(3):70-81.

\section{Publisher's Note}

Springer Nature remains neutral with regard to jurisdictional claims in published maps and institutional affiliations.
Ready to submit your research? Choose BMC and benefit from:

- fast, convenient online submission

- thorough peer review by experienced researchers in your field

- rapid publication on acceptance

- support for research data, including large and complex data types

- gold Open Access which fosters wider collaboration and increased citations

- maximum visibility for your research: over $100 \mathrm{M}$ website views per year

At BMC, research is always in progress.

Learn more biomedcentral.com/submissions 